\title{
Effect of Roasting Method on Fatty Acid Composition of Peanut Kernels
}

\author{
V.D. Sindhal ${ }^{1 *}$, N.K. Dhamsaniya ${ }^{2}$ and U.V. Patel $^{1}$ \\ ${ }^{1}$ College of Agricultural Engineering and Technology, J.A.U., Junagadh, India \\ ${ }^{2}$ Polytechnic in Agro-processing, J.A.U., Junagadh, India
}

*Corresponding author

\begin{tabular}{l} 
Ke y w o r d s \\
$\begin{array}{l}\text { Peanut roasting, Oil } \\
\text { content, Mono } \\
\text { unsaturated fatty } \\
\text { acids, Poly } \\
\text { unsaturated fatty } \\
\text { acids }\end{array}$ \\
\hline $\begin{array}{l}\text { Article Info } \\
\text { Accepted: } \\
\text { 20 June } 2019 \\
\text { Available Online: } \\
\text { 10 July } 2019\end{array}$ \\
\hline
\end{tabular}

The main objective of this study was to determine the effect of roasting method on fatty acid profile of peanut kernels. The fatty acid profile of total 9 samples was done, three of which included raw samples for three varieties of peanut, one sample of each variety from hot air oven roasting method which was roasted at $160{ }^{\circ} \mathrm{C}$ for 15 minutes and one sample of each variety for microwave oven roasting method which was roasted at $2450 \mathrm{MHz}$ for 3 minutes. For variety GJG9, saturated fatty acids for hot air oven roasted samples were lower as compared to raw and microwave oven roasted samples. However unsaturated fatty acids were higher in case of hot air oven roasted sample when compared to raw sample. Mono-unsaturated fatty acids were highest in hot air oven roasted sample and Poly-unsaturated fatty acids were highest in raw sample. For variety GG11, Mono-unsaturated fatty acids were highest in case of hot air oven roasted sample and Poly-unsaturated fatty acids were highest in microwave oven roasted sample. Whereas for variety GG20, saturated fatty acids were higher in case of hot air oven roasted samples whereas unsaturated fatty acids were higher in raw samples.

\section{Introduction}

Peanut is known as the 'Poor man's nut' which is the edible seed of legume Arachis hypogaea Linn.

The botanical name Arachis hypogaea Linn is derived from two Greek words, Arachis means 'a legume' and hypogaea means 'below ground' referring to the formation of pods in the soil (Devi et al., 2013).
Among all the nuts, peanut has an excellent nutritional profile and so it is widely used in weight management diets and meeting appropriate protein levels in the body. It has a desirable fatty acid profile for which it is used for weight management diets and is rich in vitamins, minerals and several bioactive compounds. It also contains nutrients beneficial for heart including mono unsaturated fatty acids (MUFA) and poly unsaturated fatty acids (PUFA), potassium, 
magnesium, copper, niacin, arginine, fiber, alpha-tocopherol, phytosterols and flavonoids. Important bioactive compounds like catechins and procyanidins are found in peanut skin which is known for anti-inflammatory effect on pro-inflammatory enzymes and nitrous oxide levels. Thus, it makes a substantial contribution to human nutrition (Lewis et al., 2013).

PUFA when consumed from peanuts, peanut butter and peanut oil may improve insulin sensitivity and reduce the risk of developing type-2 diabetes in women; such effects may be more effective for high-oleic peanuts due to the greater presence of MUFA. The healthpromoting effects of peanut consumption are the result of their fatty acid profiles as well as other functional constituents including vitamin E, L-arginine, soluble and insoluble fibre, phytosterols, as well as water- and lipidsoluble phenolic antioxidants. The numerous cardio protective nutrients and bioactives endogenous to peanuts and potential synergies among these components truly make the peanut a desirable plant food (Isanga and Zhang, 2007).

The search for vegetal protein sources with balanced amino acid profiles is increasing worldwide due to high cost of animal protein which is an obstacle to the access to these nutrients by developing countries populations (Aidoo et al., 2010). Animal sources are high in cholesterol which is related to occurrence of heart diseases and increased blood pressures. Also, animal sources are deficient in fibre which increases faecal weight and the absence of fibre causes constipation problems. Human beings, as well as the majority of animals, cannot synthesize essential amino acids which must be obtained through the diet. Plant proteins serve as abundant sources of antioxidants and are easy to digest, free from certain allergens thus giving additional reasons for its mass use over costlier animal proteins. The linoleic fatty acids (belonging to omega- 6 family of fatty acids) and $\alpha$-linolenic fatty acids (belonging to omega-3 family of fatty acids) are considered essential as they cannot be synthesized and must be taken from food. Peanuts have high levels of protein that is more readily available when compared with protein from other sources (Mutegi et al., 2009).

The chemical and physical properties of fats and oils are mainly determined by the fatty acids that they contain and their position within the triacylglycerol (TAG) molecule. Peanut oil is pale-yellow oil with distinctive nutty taste and odour obtained from the processing of peanut kernel, but odour is almost removed with refining (Sanders, 2002). It has a high oleic content that is associated with its good oxidative and frying stabilities. It is non-drying oil that solidifies from 0 to $3^{\circ} \mathrm{C}$ (O'Brien, 2004). It is considered to be more desirable dietary ingredient than saturated animal fats because they help to improve blood vessel elasticity, keeps the heart rhythm beating normally, thin the blood, which makes it less sticky and less likely to clot and support the immune system (Bucher et al., 2002).

Roasted peanuts is one of the most popular snack foods, in which roasting is a key step in the process that directly impacts its quality especially crispness, taste and flavour as well as shelf-life of the final product. In roasted peanuts, the volatiles are formed as a result of Maillard reaction, strecker degradation, caramelization of sugar and lipid oxidation (Chen et al., 2010). The current practice of roasting peanut kernels is based mainly on color development. But, the flavor is more important than the color and so the traditional roasting process needs to be standardized (Dhamsaniya and Patel, 2013).

The critical roasting parameters (roasting time and temperature) greatly influence the roasted 
product characteristics. As roasting time or temperature increases, the brown melanin colour intensifies in peanuts (Raigar et al., 2017). The content of biological molecules such as free amino acids and peptides, fatty acids, phytosterols, lignans and vitamins changes during the roasting process. So it is necessary to understand the effect of roasting on fatty acid composition of peanut kernels which is the main objective of this research.

\section{Materials and Methods}

\section{Sample collection and preparation}

Among the various cultivars of peanut, three peanut cultivars namely GJG9, GG11 and GG20 were selected on the basis of growing condition as bunch, spreading and semispreading type in order to understand the mechanism of roasting and identify the optimum condition for enhancing the roasting quality of peanut kernels.

The pods of the selected peanut cultivars were procured in the required quantity from the Main Oilseeds Research Station of Junagadh Agricultural University, Junagadh. The pods were decorticated manually to obtain whole kernels with minimum damage. The immature, rotten and scorched kernels were removed manually to obtain sound and healthy kernels for various investigations.

\section{Method employed for roasting}

The peanut kernels were roasted using two different roasting methods namely hot air oven roasting and microwave oven roasting. For hot air oven roasting, temperature was kept $160{ }^{\circ} \mathrm{C}$ and the roasting durations were varied as 15 minutes, 30 minutes and 45 minutes. Microwave oven roasting was carried out at $2450 \mathrm{MHz}$ frequency with three different roasting durations i.e., 3 minutes, 4 minutes and 5 minutes. Hence, the combination of three different varieties, two different methods and three different roasting durations resulted in total 18 treatments (Table 2 and 3 ).

\section{Moisture content}

The moisture content (wet basis) of peanut kernels was determined by hot air oven drying method. The peanut kernels were kept in a single layer in Petri dishes and then the dishes were placed inside a hot air oven at $130^{\circ} \mathrm{C}$ for 6 hour till the samples attained the constant weight. The samples were cooled in desiccators and weighed. The difference in initial and final weights of the samples was taken as the weight of water removed. The moisture content of whole peanut kernels was calculated by dividing the weight of water removed by the total weight of the sample and expressed in percent wet basis. It was calculated by using the formula given below,

Moisture content $(\%)=\frac{\text { Weight of water removed }(\mathrm{g})}{\text { Initial weight }(\mathrm{g})} \times 100$

\section{Oil content}

Oil content was determined by soxhlet method (Socs plus, Model: SCS 06 AS DLS). For oil content determination, the peanut kernel was grounded with mortar and pestle and $2 \mathrm{~g}$ of sample was weighed. This sample was transferred to the cellulose thimble. The initial weight of the flask was taken where the oil is extracted. Then, the thimble was fixed to the thimble holder after which it was placed into the beaker. After which, $80 \mathrm{ml}$ of solvent (petroleum ether, boiling point temperature $60-80{ }^{\circ} \mathrm{C}$ ) was added and the beaker was inserted with solvent in the extraction system. Proper sealing of beaker was ensured. The water inlet was connected and the water was flowed through the system. The power was switched on and the temperature was set 100 ${ }^{\circ} \mathrm{C}$ for first step of one hour's boiling and 120 ${ }^{\circ} \mathrm{C}$ for second step of half hour's evaporation 
of solvent. After compete evaporation of solvent the beaker was taken out from the system and thimble was removed from the beaker. The beaker was kept inside the hot air oven for few minutes to remove solvent vapours. The final weight of the beaker was taken and the oil content of sample taken in thimble was calculated using following equation,

Oil content $(\%)=\frac{(\text { Weight of flask }+ \text { oil })-(\text { Weight of empty flask })}{\text { Weight of sample }} \times 100$

\section{Fatty acid profile}

The fatty acids were analysed by the method suggested by Misra and Mathur (1998). For this, methyl esters were prepared. In a10 ml screw cap test tube, $200 \mu \mathrm{l}$ oil was mixed with $3 \mathrm{ml}$ hexane kept for $1 \mathrm{~h}$ at room temperature with intermittent vortexing. In the same tube, $3 \mathrm{ml}$ of freshly prepared Sodium methoxide (80 mg NaOH in $100 \mathrm{ml}$ methanol) was added and incubated at room temperature for $30 \mathrm{~min}$ followed by addition of $3 \mathrm{ml}$ of $0.8 \%$ aqueous sodium chloride and then shacked well. After $5 \mathrm{~min}$, the upper hexane layer containing the methyl-esters were transferred to another centrifuge tube already containing $100 \mathrm{mg}$ anhydrous sodium sulphate.

A Shimadzu Gas Chromatograph (GC-2010) system comprising of an AOC-20i autosampler and interfaced to a mass spectrometer (QP Plus 2010) equipped with a polar fused capillary column, DB-Wax (100\% Polyethylene Glycol, 30 meter Length x 0.25 mm ID x $0.25 \mu \mathrm{m} \mathrm{df}$ ) was used for fatty acid profiling. For GC-MS detection, an Electron Ionization system was operated in Electron Impact (EI) mode with ionization energy of 70 eV. Helium gas (99.999\% purity) was used as a carrier gas at a constant flow rate of 1 $\mathrm{ml} / \mathrm{min}$ and an injection volume of $1 \mu \mathrm{l}$ was employed with a split ratio of $50: 1$. The injector temperature was maintained at $250{ }^{\circ} \mathrm{C}$, the Ion-Source temperature at $230{ }^{\circ} \mathrm{C}$. The column oven temperature was programmed from $60^{\circ} \mathrm{C}$ with an increase of $12{ }^{\circ} \mathrm{C} / \mathrm{min}$ to $150{ }^{\circ} \mathrm{C}$ and then was increased at a rate of 5 ${ }^{\circ} \mathrm{C} / \mathrm{min}$ to $240{ }^{\circ} \mathrm{C}$ (isothermal for $5 \mathrm{~min}$ ). Mass spectra were taken for fragments ranging from $50 \mathrm{~m} / \mathrm{z}$ to $1000 \mathrm{~m} / \mathrm{z}$. Identification of the Fatty Acid Methyl Ester was conducted by comparing the mass spectrum with NIST library. The compound showing more than 90\% Similarity Index (SI) was identified and recorded. The fatty acid composition was reported as a relative percentage of the total peak area. This method was suggested by Rathod et al., (2017).

\section{Results and Discussion}

\section{Moisture content}

The moisture content for hot air oven roasted peanut kernels decreased in the range of 2.9 to 0.4 per cent whereas as that of microwave oven roasted peanut kernels was reduced in the range of 3.5 to 2.0 per cent. The decrease in moisture content for hot air oven roasting method was higher than microwave oven roasting. The moisture loss tends to increase with increase in roasting time. This indicated that the peanut kernels have been heated to boiling temperature of water, causing evaporation to take place.

\section{Oil content}

The oil content of roasted peanut kernels decreased with increase in roasting time. The decrease in oil content with roasting time can be related to moisture content i.e., as roasting duration increases, moisture content decreases leading to hardening of cells which makes it difficult for oil to expel. The higher oil content was observed for treatments of all the three varieties roasted at $15 \mathrm{~min}$ (Fig. 1 and 2) and it decreased as time increased from 15-45 min. 


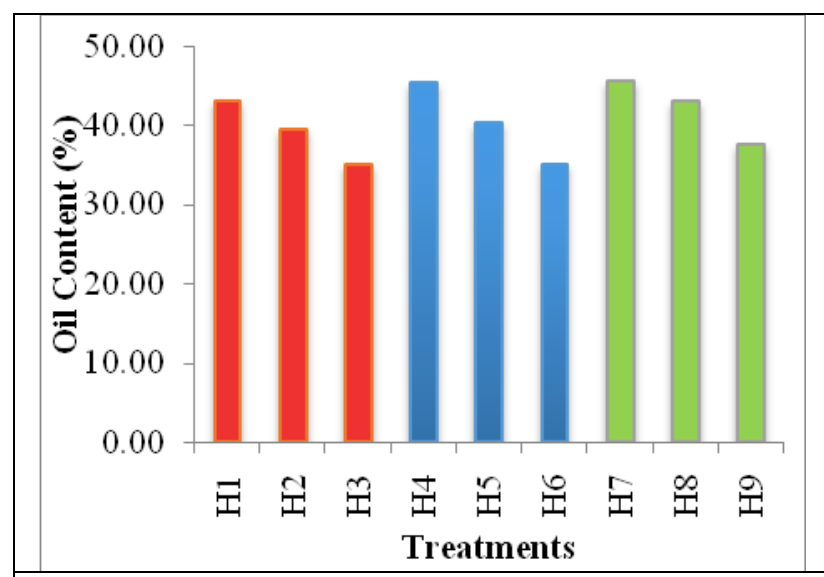

Fig.1 Effect of hot air oven roasting duration on oil content of roasted peanut kernels

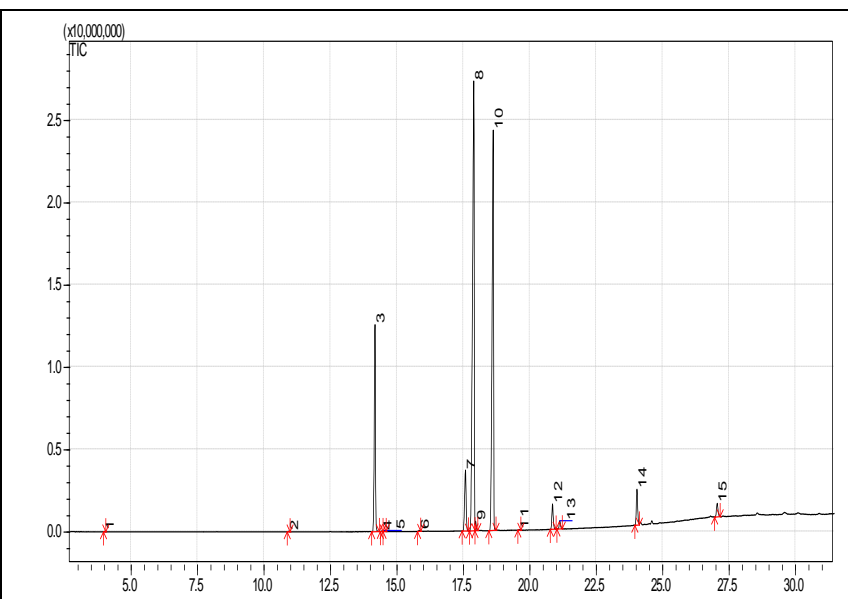

Fig.3 Chromatogram for fatty acid profile of hot air oven roasted peanut kernel of variety GJG9

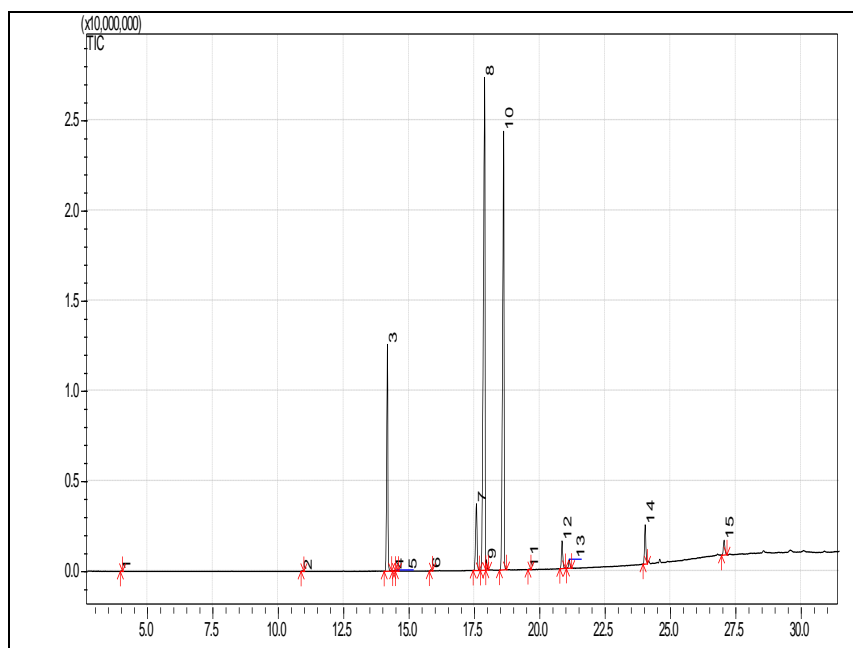

Fig.5 Chromatogram for fatty acid profile of hot air oven roasted peanut kernel of variety GG11

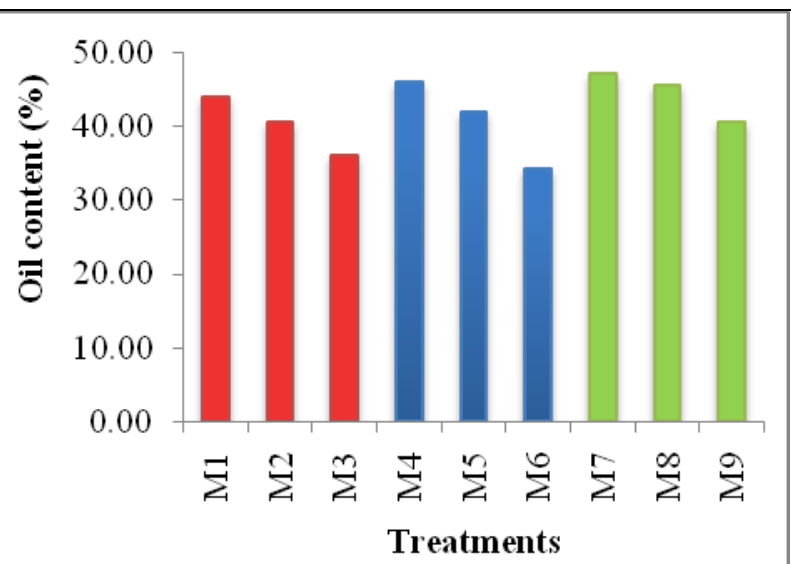

Fig.2 Effect of microwave oven roasting duration on oil content of roasted peanut kernels

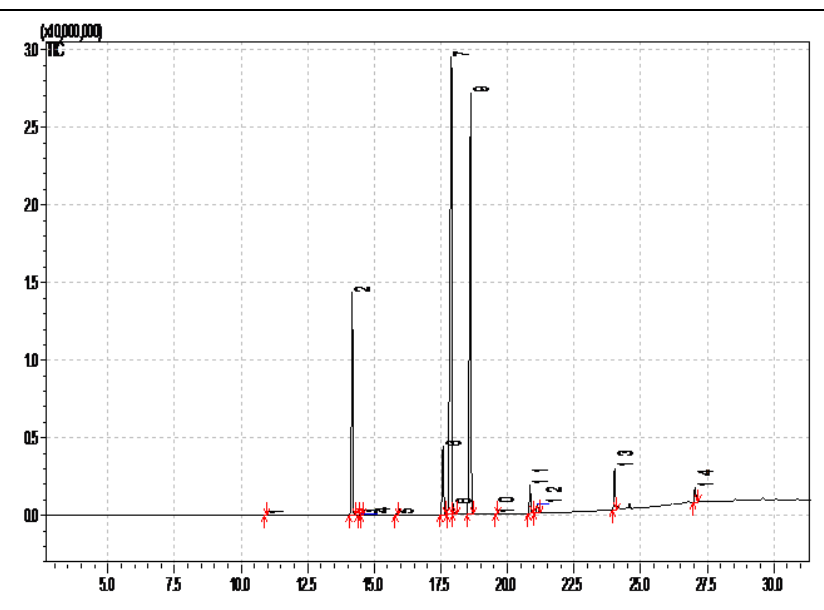

Fig.4 Chromatogram for fatty acid profile of microwave air oven roasted peanut kernel of variety GJG9

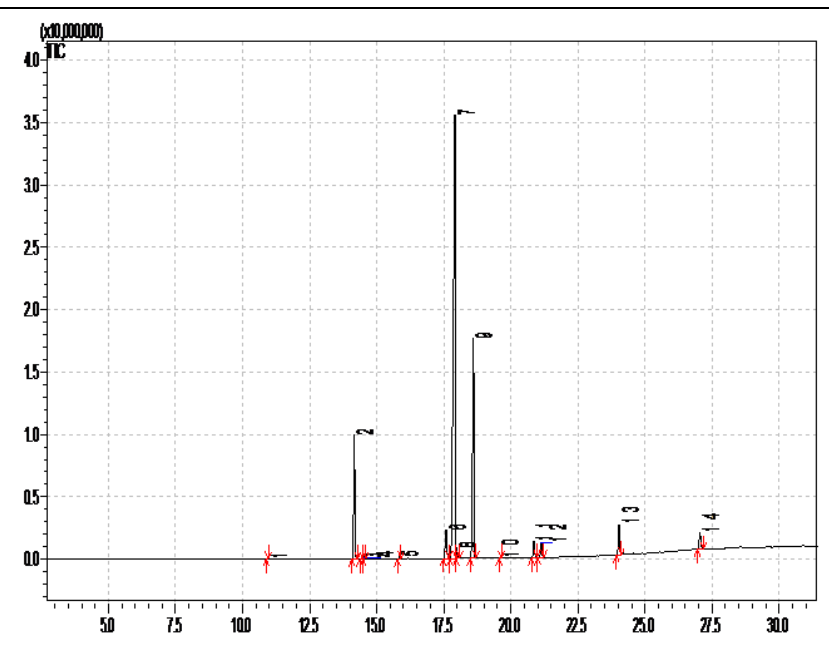

Fig.6 Chromatogram for fatty acid profile of microwave air oven roasted peanut kernel of variety GG11 


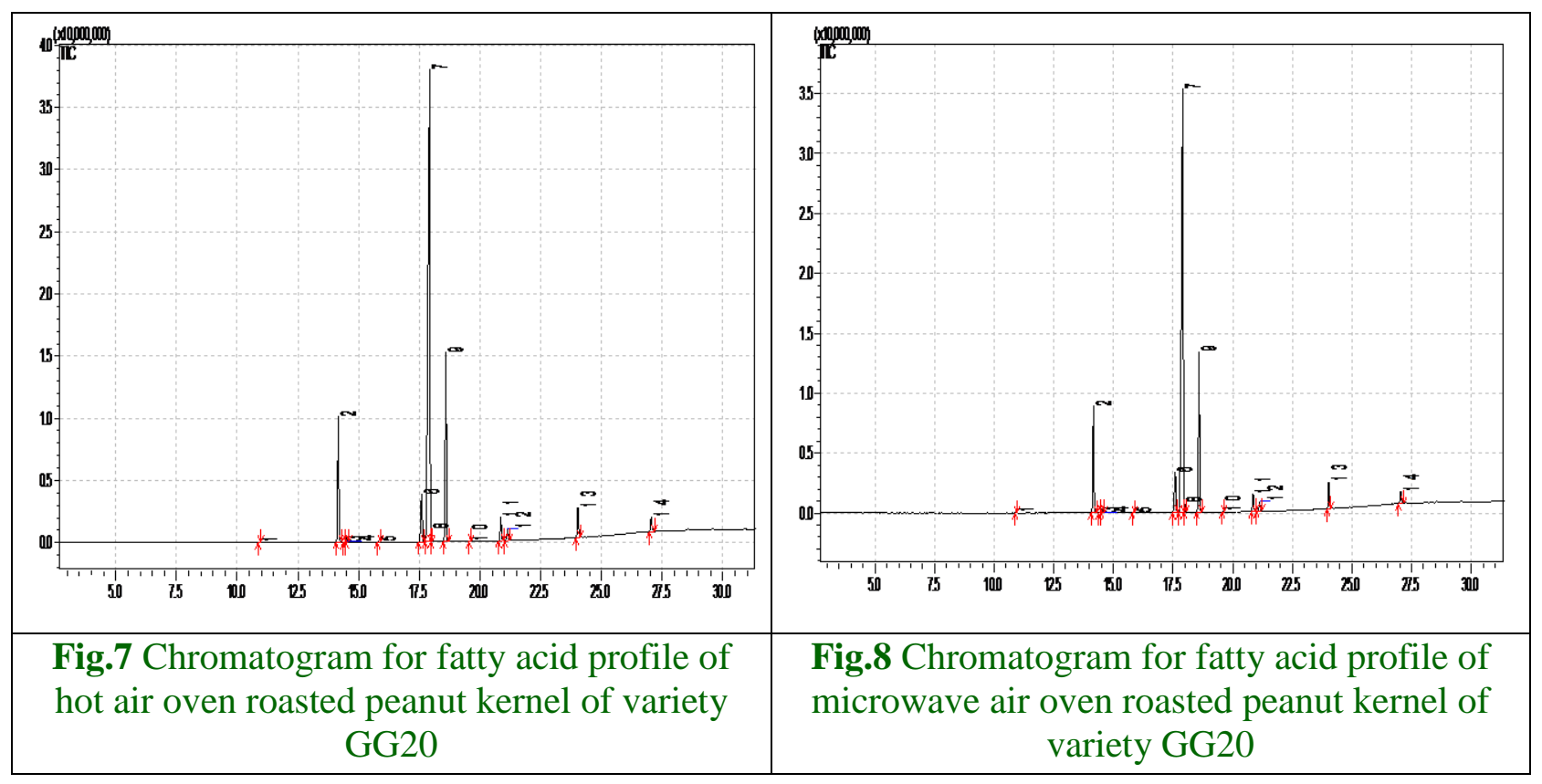

Table.1 Fatty acid profiling of raw and roasted peanut kernel's oil of selected varieties

\begin{tabular}{|c|c|c|c|}
\hline \multirow[t]{2}{*}{ Types of Fatty acids } & \multicolumn{3}{|c|}{ Relative content (\%) } \\
\hline & $\begin{array}{c}\text { Raw } \\
\text { sample }\end{array}$ & $\begin{array}{l}\text { Hot air oven } \\
\text { roasted }\end{array}$ & $\begin{array}{c}\text { Microwave oven } \\
\text { roasted }\end{array}$ \\
\hline \multicolumn{4}{|l|}{ Variety GJG9 } \\
\hline Saturated Fatty acids & 24.90 & 24.29 & 24.94 \\
\hline Unsaturated Fatty acids & 75.10 & 75.71 & 75.06 \\
\hline Mono-Unsaturated Fatty acids & 41.68 & 43.40 & 41.96 \\
\hline Poly-Unsaturated Fatty acids & 33.42 & 32.31 & 33.10 \\
\hline \multicolumn{4}{|l|}{ Variety GG11 } \\
\hline Saturated Fatty acids & 18.77 & 18.56 & 18.55 \\
\hline Unsaturated Fatty acids & 81.23 & 81.44 & 81.45 \\
\hline Mono-Unsaturated Fatty acids & 61.87 & 62.07 & 61.75 \\
\hline Poly-Unsaturated Fatty acids & 19.36 & 19.37 & 19.70 \\
\hline \multicolumn{4}{|l|}{ Variety GG20 } \\
\hline Saturated Fatty acids & 19.90 & 20.09 & 20.03 \\
\hline Unsaturated Fatty acids & 80.10 & 79.91 & 79.97 \\
\hline Mono-Unsaturated Fatty acids & 64.92 & 64.90 & 65.20 \\
\hline Poly-Unsaturated Fatty acids & 15.18 & 15.01 & 14.77 \\
\hline
\end{tabular}


Table. 2 Treatment combinations for hot air oven roasting

\begin{tabular}{|c|c|c|}
\hline Sr. No. & Treatments & Combinations \\
\hline $\mathbf{1}$ & H1 & Variety1 (GJG9) + time1 $(15 \mathrm{~min})$ \\
\hline $\mathbf{2}$ & H2 & Variety1 (GJG9) + time2 $(30 \mathrm{~min})$ \\
\hline $\mathbf{3}$ & H3 & Variety1 (GJG9) + time3 $(45 \mathrm{~min})$ \\
\hline $\mathbf{4}$ & H4 & Variety2 (GG11) + time1 $(15 \mathrm{~min})$ \\
\hline $\mathbf{5}$ & H5 & Variety2 $(\mathrm{GG} 11)+$ time2 $(30 \mathrm{~min})$ \\
\hline $\mathbf{6}$ & H6 & Variety2 $(\mathrm{GG} 11)+$ time3 $(45 \mathrm{~min})$ \\
\hline $\mathbf{7}$ & H7 & Variety3 $(\mathrm{GG} 20)+$ time1 $(15 \mathrm{~min})$ \\
\hline $\mathbf{8}$ & H8 & Variety3 $(\mathrm{GG} 20)+$ time2 $(30 \mathrm{~min})$ \\
\hline $\mathbf{9}$ & H9 & Variety $3(\mathrm{GG} 20)+$ time3 $(45 \mathrm{~min})$ \\
\hline
\end{tabular}

Table.3 Treatment combinations for microwave oven roasting

\begin{tabular}{|c|c|c|}
\hline Sr. No. & Treatments & Combinations \\
\hline $\mathbf{1}$ & M1 & Variety1 (GJG9) + time1 $(3 \mathrm{~min})$ \\
\hline $\mathbf{2}$ & M2 & Variety1 (GJG9) + time2 $(4 \mathrm{~min})$ \\
\hline $\mathbf{3}$ & M3 & Variety1 $(\mathrm{GJG} 9)+$ time3 $(5 \mathrm{~min})$ \\
\hline $\mathbf{4}$ & M4 & Variety2 $(\mathrm{GG} 11)+$ time1 $(3 \mathrm{~min})$ \\
\hline $\mathbf{5}$ & M5 & Variety2 $(\mathrm{GG} 11)+$ time2 $(4 \mathrm{~min})$ \\
\hline $\mathbf{6}$ & M6 & Variety2 $(\mathrm{GG} 11)+$ time3 $(5 \mathrm{~min})$ \\
\hline $\mathbf{7}$ & M7 & Variety3 $(\mathrm{GG} 20)+$ time1 $(3 \mathrm{~min})$ \\
\hline $\mathbf{8}$ & M8 & Variety3 $(\mathrm{GG} 20)+$ time2 $(4 \mathrm{~min})$ \\
\hline $\mathbf{9}$ & M9 & Variety3 $(\mathrm{GG} 20)+$ time3 $(5 \mathrm{~min})$ \\
\hline
\end{tabular}

The data for microwave oven method revealed results similar to hot air oven method. However, the decrease in oil content with roasting time was less in this method which is also related to moisture content. The moisture content of microwave roasted peanut kernels was higher than oven roasted peanut kernels which yielded relatively higher oil content (Fig. 3-7).

\section{Fatty acid profile}

The fatty acid profile of total 9 samples was done, three of which included raw samples for three varieties of peanut, one sample of each variety from hot air oven roasting method and one sample of each variety for microwave oven roasting method. The data for fatty acid profile are given in Table 1.
The comparison between fatty acids of raw and roasted samples for variety GJG9 is given in Table 1. The data revealed that saturated fatty acids for hot air oven roasted samples were lower as compared to raw and microwave oven roasted samples. However unsaturated fatty acids were higher in case of hot air oven roasted sample when compared to raw sample; whereas that of microwave oven roasted peanuts where lower than both raw as well as hot air oven roasted sample. Mono-unsaturated fatty acids (MUFA) were highest in hot air oven roasted sample and Poly-unsaturated fatty acids (PUFA) were highest in raw sample.

The results for fatty acid profile of raw and roasted peanut kernels oil of variety GG11 showed that saturated fatty acids were higher 
in case of raw sample. There was a minor difference in unsaturated fatty acids i.e., they were slightly higher in case of both the roasting methods when compared to raw sample. Mono-unsaturated fatty acids (MUFA) were highest in case of hot air oven roasted sample and Poly-unsaturated fatty acids (PUFA) were highest in microwave oven roasted sample.

As per data for raw and roasted samples of variety GG20 shown in Table 1, it can be observed that saturated fatty acids were higher in case of hot air oven roasted samples whereas unsaturated fatty acids were higher in raw samples. There was slight difference in Mono-unsaturated fatty acids (MUFA) and it was noted highest in case of microwave oven roasted sample. The results for Polyunsaturated fatty acids (PUFA) showed that there was minor difference between raw and hot air oven roasted samples, whereas microwave oven roasted samples showed lowest Poly-unsaturated fatty acids.

The data revealed that saturated fatty acids for hot air oven roasted samples were lower as compared to raw and microwave oven roasted samples. However unsaturated fatty acids were higher in case of hot air oven roasted sample when compared to raw sample; whereas that of microwave oven roasted peanuts where lower than both raw as well as hot air oven roasted sample. Monounsaturated fatty acids (MUFA) were highest in hot air oven roasted sample and Polyunsaturated fatty acids (PUFA) were highest in raw sample.

It can be concluded that mono unsaturated fatty acids were highest for hot air roasted samples of variety GJG9 whereas poly unsaturated fatty acids were highest in raw samples. However for variety GG11, there was a minor difference in unsaturated fatty acids i.e., they were slightly higher in case of both the roasting methods when compared to raw sample. Whereas for variety GG20, unsaturated fatty acids were higher for raw sample.

\section{References}

Aidoo, H., Sakyi-Dawson, E., Tano-Debra, K. and Saalia, F.K. 2010. Development and characterization of dehydrated peanut-cowpea milk powder for use as a dairy milk substitute in chocolate manufacture. Food Research International, 43: 79-85.

Bucher, H. C., Hengstler, P., Schindler, C. and Meier, G. 2002. n-3 polyunsaturated fatty acids in coronary heart disease: a meta-analysis of randomized controlled trials. Am. J. Med., 112(4): 298-304.

Chen, T., Kang, B., Chen, S., Chen, H. and Lin, H. 2010. Optimized parameters and quality analysis of salty and crisp peanut by far infrared roasting. Transactions of the Chinese Society of Agricultural Engineering, 26(8): 320325.

Devi, K. B., Vidhya, R. and Jaganmohan, R. 2013. Determination and isolation of protein from different fractions of defatted groundnut oil cake. Afr. J. Plant Sci., 7(8): 394-400.

Dhamsaniya, N. K. and Patel, N. C. 2013. Standardizing peanut roasting process of peanut butter production. International Journal of Engineering Research and Technology, 2(6): 714-17.

Isanga, J. and Zhang, G.N. 2007. Biologically active components and nutraceuticals in peanuts and related products: Review. Food Rev. Int., 23: 123-140.

Lewis, W. E., Harris, G. K., Sanders, T. H., White, L. B. and Dean, L. L. 2013. Antioxidant and anti-inflammatory effects of peanut skin extracts. Biomed. Life Sci., 4(8) (A): 22-32. 
Misra, J. B. and Mathur, R. S. 1998. A simple and economic procedure for transmethylation of fatty acids of groundnut oil for analysis by GLC. International Arachis Newsletter, 18: 40-42.

Mutegi, C.K., Ngugi, H.K., Hendriks, S.L. and Jones, R.B. 2009. Prevalence and factors associated with aflatoxin contamination of peanuts from western Kenya. International Journal of Food Microbiology, 130: 27-34.

O’Brien, R.D. 2004. Fats and Oils. Formulating and Processing for Applications. CRC press, Boca Raton, USA.

Raigar, R. K., Upadhyay R. and Mishra, H. N. 2017.Optimization of microwave roasting of peanuts and evaluation of its physicochemical and sensory attributes. Journal of Food Science and Technology, 54(7): 2145-2155.

Rathod, K. J., Jadeja, B. A., Jadav, J. K. and Golakiya, B. A. 2017. Physico-chemical characterization and fatty acid profiling of seed oils of grain amaranthus cultivars of India-A nutritional perspective. Int. J. Pure App. Biosci., 5(4): 1424-1432.

Sanders, T.H. 2002. Groundnut (peanut) oil, In: Gunstone FD (Ed.), Vegetable Oils in Food Technology. Composition, Properties and Uses. Blackwell Publishing Ltd, Oxford, UK, pp. 231243.

\section{How to cite this article:}

Sindhal, V.D., N.K. Dhamsaniya and Patel, U.V. 2019. Effect of Roasting Method on Fatty Acid Composition of Peanut Kernels. Int.J.Curr.Microbiol.App.Sci. 8(07): 2581-2589. doi: https://doi.org/10.20546/ijcmas.2019.807.318 